\title{
EFFECTS OF LOW ANGLE BOUNDARIES ON THE MECHANICAL PROPERTIES OF SINGLE CRYSTAL SUPERALLOY DD6
}

\author{
J.R. Li, J.Q. Zhao, S.Z. Liu, M. Han \\ National Key Laboratory of Advanced High Temperature Structural Materials, Beijing Institute of Aeronautical Materials; \\ P.O. Box 81-1; Beijing, 100095, P.R. China
}

Keywords: Single crystal superalloy, DD6, Low angle boundary, Tensile, Creep, Fracture

\begin{abstract}
During the solidification/growth of single crystal blades and vanes, defects in the form of both high angle boundaries and low angle boundaries occasionally form. High angle boundaries (HAB) often result in rejection of a casting. Low angle boundaries (LAB) are tolerated within production casting to a certain extent. LABs within a single crystal affect the mechanical response of the material and thus the quality of the blade or vane. This work assesses the effect of LABs on the mechanical properties of the second generation single crystal superalloy DD6. Bicrystal slabs with low angle tilt boundaries were cast using seed techniques. Specimens for tensile and creep testing were machined from these slabs with the $\mathrm{LAB}$ misorientations varying from $0^{\circ}$ to $12^{\circ}$. The material characterization was carried out by optical microscopy (OM) and scanning electron microscopy (SEM).
\end{abstract}

It is notable that the effects of LAB on the ultimate tensile strength are weaker than those on the tensile elongation. The results show that when the misorientation angle of the $\mathrm{LAB}$ is less than $9^{\circ}$, the LAB has a relatively minor affect on the ultimate tensile strength at a given temperature. The elongation of the alloy however shows a significant decrease at a given temperature with increasing $\mathrm{LAB}$ orientation angle. The creep rupture properties of the alloy with $\mathrm{LAB}$ were performed at $800^{\circ} \mathrm{C}, 850^{\circ} \mathrm{C}, 900^{\circ} \mathrm{C}$ and $980^{\circ} \mathrm{C}$. In general under a given set of test conditions, the creep rupture life decreases with increasing LAB misorientation.

Features characteristic of both quasi-cleaveage and intergranular mechanisms were observed on the fracture surfaces of the specimens with LABs. Both the [001] fracture surfaces, as well as the fracture surfaces on the specimens with LABs had rectangular dimples. It is hypothesized that the rectangular dimples were created as fracture occurs on $\{111\}$ planes. The specimens with LABs appear to fail initially in an intergranular manner, followed by mode that creates quasi-cleavage surface features.

\section{Introduction}

Because single crystal superalloys offer improved creep rupture, fatigue, environmental and coating properties, resulting in superior turbine engine performance and durability, the application of single crystal turbine components increased remarkably in advanced propulsion systems [1-6]. High angle boundary (HAB) and low angle boundary (LAB) are apt to form in the blades and vanes of single crystal superalloys. The presence of $\mathrm{HAB}$ defects is one of the principal factors, contributing to casting rejection. Low angle boundary has obvious effects on the mechanical properties and quality of the single crystal blades and vanes [4,6-8]. In casting blades and vanes of single crystal superalloys, it is impossible to maintain perfect [001] crystal orientation. Considered less deleterious are the low angle grain boundaries that form between essentially parallel single crystals, so some levels of low angle boundaries are always accepted. The objective of the program was to assess the effects of low angle boundary on the mechanical properties of a low-cost second generation single crystal superalloy, DD6, developed for aeroengine blade applications [9]. The research results of the effects of LAB on the mechanical properties of DD6 alloy are reported in this paper.

\section{Experimental Procedure}

\section{Materials}

DD6 contains 2 wt.\% rhenium, which is about $2 / 3$ that of other second generation single crystal superalloys, such as PWA1484, CMSX-4 and René N5. The tensile properties, creep rupture properties and fatigue properties of DD6 alloy are equivalent to those of other second generation single crystal superalloys $[9,10]$. Most notably, DD6 alloy provides superior oxidation resistance and good hot corrosion resistance, and excellent castability [9]. The master alloy heat of DD6 was melted in a vacuum induction furnace according to a well established procedure. The nominal compositions of DD6 alloy used in the study are listed in Table I.

Table I Nominal compositions of DD6 alloy (wt. \%)

\begin{tabular}{|c|c|c|c|c|}
\hline $\mathrm{Cr}$ & $\mathrm{Co}$ & $\mathrm{Mo}$ & $\mathrm{W}$ & $\mathrm{Re}$ \\
\hline 4.3 & 9 & 2 & 8 & 2 \\
\hline $\mathrm{Ta}$ & $\mathrm{Nb}$ & $\mathrm{Al}$ & $\mathrm{Hf}$ & $\mathrm{C}$ \\
\hline 7.5 & 0.5 & 5.6 & 0.1 & 0.006 \\
\hline
\end{tabular}

$\underline{\text { Test Methods }}$

Directional solidification of single crystal superalloys can result in the creation of low angle boundaries which are mainly tilt boundaries in blades and vanes. Bicrystal slabs with low angle tilt boundaries were cast using seeds with a [001] orientation. The misorientation of the $\mathrm{LAB}$ was achieved by rotating one of the seeds, relative to the other seed. The crystal orientation and grain boundary misorientation of the slabs were verified with Laue $\mathrm{XRD}$ and the misorientation angle was calculated. The test specimens for tensile and creep testing were machined from fully heat treated slabs with the misorientation $(\theta)$ of LAB varying from $0^{\circ}$ to $12^{\circ}$. The schematic of the testing specimen of DD6 alloy with $\mathrm{LAB}$ is shown in Figure 1. The stress state in the rabbet is complex, which results in that a LAB in the rabbet would sustain tension load. Considering both tensile stress and mechanical properties of LABs, the LABs are transverse to the load axis in the specimens. If the misorientation of LAB is zero, then the LAB is a primary dendrite boundary, or in other words the property of zero misorientation with a $\mathrm{LAB}$ is theoretically the transverse 
property of single crystal superalloy. The tensile tests were conducted at $800^{\circ} \mathrm{C}, 850^{\circ} \mathrm{C}, 900^{\circ} \mathrm{C}, 950^{\circ} \mathrm{C}$ and $980^{\circ} \mathrm{C}$. The creep tests were conducted at $800^{\circ} \mathrm{C} / 700 \mathrm{MPa}, 850^{\circ} \mathrm{C} / 550 \mathrm{MPa}$, $900^{\circ} \mathrm{C} / 450 \mathrm{MPa}$ and $980^{\circ} \mathrm{C} / 250 \mathrm{MPa}$. Material characterization was carried out by optical microscopy (OM) and scanning electron microscopy (SEM).

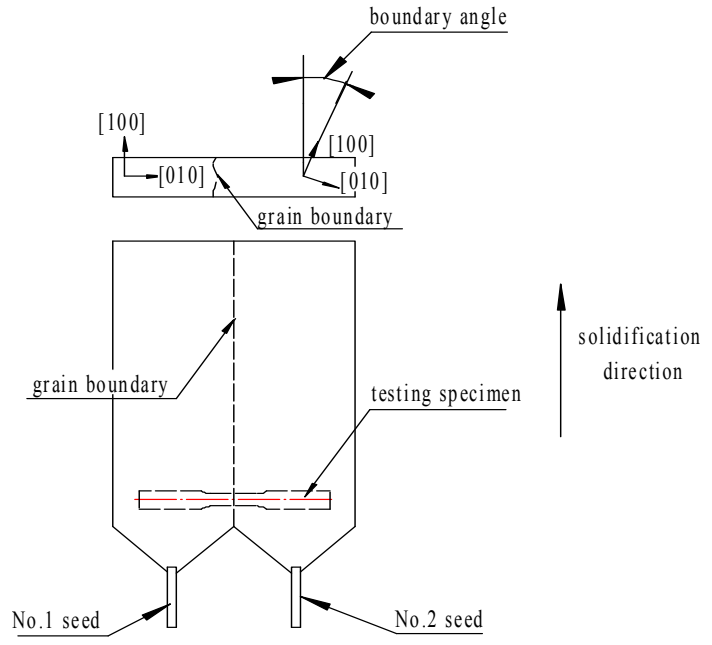

Figure 1. Schematic of the testing specimen of DD6 alloy with LAB.

The slabs of DD6 alloy with LAB were fully heat treated before machined into testing specimens, and the heat treatment regime is as follows: $1290^{\circ} \mathrm{C} / 1$ hour $+1300^{\circ} \mathrm{C} / 2$ hours $+1315^{\circ} \mathrm{C} / 4$ hours $/ \mathrm{AC}$ $+1120^{\circ} \mathrm{C} / 4$ hours $/ \mathrm{AC}+870^{\circ} \mathrm{C} / 32$ hours/AC [10]. The heat treatment regime for DD6 was carefully studied to provide acceptable microstructure and optimal mechanical properties.

\section{Results and Discussion}

\section{$\underline{\text { Initial Microstructures }}$}

The microstructures of the DD6 alloy with LABs in the as-cast condition are shown in Figure 2. The grain boundary misorientation angle of this specimen is $8^{\circ}$. These specimens were electrolytically etched to allow the low angle boundary to be observed. The $\gamma^{\prime}$ phase in the interdendritic regions tends to be irregular while the $\gamma^{\prime}$ phase in the dendritic cores tends to be cuboidal.

The microstructures of DD6 alloy with LABs in the fully heat treated are shown in Figure 3. The grain boundary misorientation angles of these specimens are $5.5^{\circ}$ and $11.5^{\circ}$, respectively. The specimen with the grain boundary misorientation of $11.5^{\circ}$ was electrolytically etched. The cubic shape of $\gamma^{\prime}$ phase in the interface is not perfect owing to the restriction of $\mathrm{LAB}$, and the orientation of the $\gamma^{\prime}$ phase in one side is different from that in another side of the interface.

\section{$\underline{\text { Tensile Properties }}$}

Ultimate Tensile Strength and Elongation. The casting yield of the slabs for the bicrystals is low because it is difficulty to achieve the desired LAB misorientation angle $(\theta)$. The misorientation angle of $\mathrm{LAB}$ of the specimens varies from $0^{\circ}$ to $12^{\circ}$, and the range of the

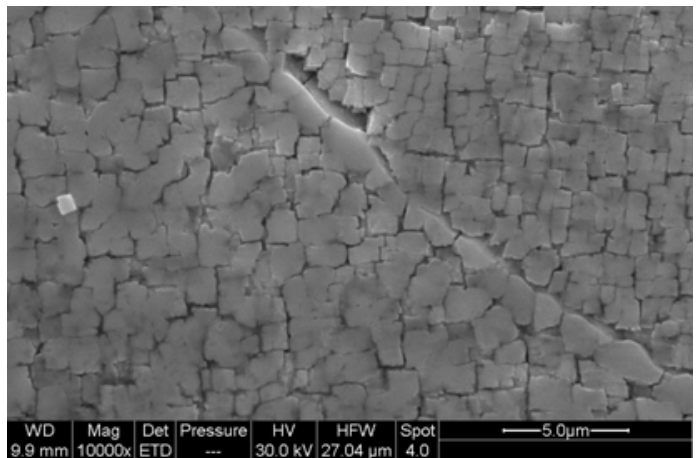

(a)

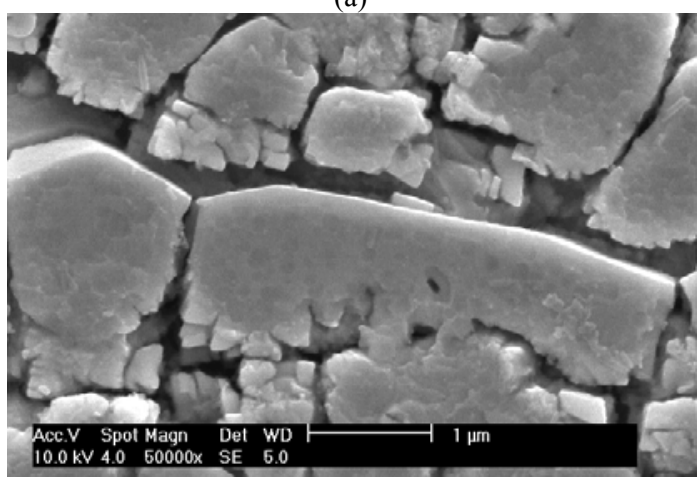

(b)

Figure 2. Microstructures of DD6 alloy with LABs in the as-cast (a) $8^{\circ}$ at low magnification; (b) $8^{\circ}$ at high magnification.

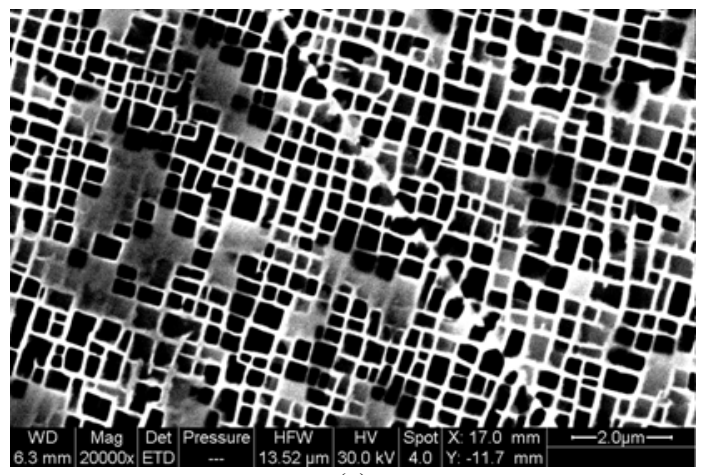

(a)

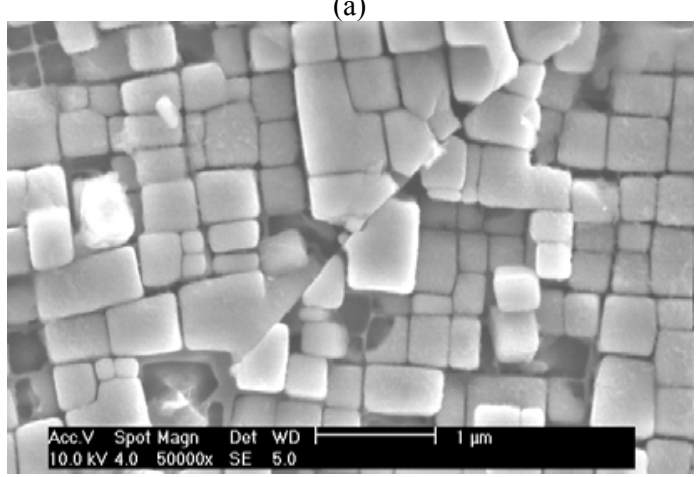

(b)

Figure 3. Microstructures of DD6 alloy with LABs in the fully heat treated (a) $5.5^{\circ}$ at low magnification; (b) $11.5^{\circ}$ at high magnification. 
misorientation angle of LAB is classified into four groups. The orientation paralleling [001] direction with no LAB is expressed as [001]. The class of the specimens is listed in Table II.

Table II Class of the specimens with and no LAB

\begin{tabular}{|c|c|c|c|c|}
\hline $\begin{array}{c}\text { Paralleling [001] } \\
\text { with no LAB }\end{array}$ & $0^{\circ} \leq \theta<3^{\circ}$ & $3^{\circ} \leq \theta<6^{\circ}$ & $6^{\circ} \leq \theta<9^{\circ}$ & $9^{\circ} \leq \theta<12^{\circ}$ \\
\hline$[001]$ & $\mathrm{XS}$ & $\mathrm{S}$ & $\mathrm{M}$ & $\mathrm{L}$ \\
\hline
\end{tabular}

Table III lists the tensile properties of the DD6 specimens with LABs and [001] orientation at $800^{\circ} \mathrm{C}, 850^{\circ} \mathrm{C}, 900^{\circ} \mathrm{C}, 950^{\circ} \mathrm{C}$ and $980^{\circ} \mathrm{C}$. The effects of LAB on the ultimate tensile strength (UTS) are shown in Figure 4. The test results show that LAB has little effect on the ultimate tensile strength (UTS) at $800^{\circ} \mathrm{C}$. With the increase of temperature, the ultimate tensile strength decreases in the same misorientation. Increasing the LAB misorientation has a distinct but minor affect on the UTS as the temperature increases when the misorientation is $0^{\circ}<\theta<9^{\circ}$.

Table III Tensile properties of the specimens of DD6 alloy with LAB and [001] orientation

\begin{tabular}{|c|c|c|c|c|c|c|c|c|c|c|}
\hline \multirow[b]{2}{*}{ Specimen } & \multicolumn{2}{|c|}{$800^{\circ} \mathrm{C}$} & \multicolumn{2}{|c|}{$850^{\circ} \mathrm{C}$} & \multicolumn{2}{|c|}{$900^{\circ} \mathrm{C}$} & \multicolumn{2}{|c|}{$950^{\circ} \mathrm{C}$} & \multicolumn{2}{|c|}{$980^{\circ} \mathrm{C}$} \\
\hline & $\begin{array}{l}\text { UTS, } \\
\text { MPa }\end{array}$ & $\begin{array}{c}\text { Elong, } \\
\%\end{array}$ & $\begin{array}{l}\text { UTS, } \\
\text { MPa }\end{array}$ & $\begin{array}{c}\text { Elong, } \\
\%\end{array}$ & $\begin{array}{l}\text { UTS, } \\
\text { MPa }\end{array}$ & $\begin{array}{c}\text { Elong, } \\
\%\end{array}$ & $\begin{array}{l}\text { UTS, } \\
\mathrm{MPa}\end{array}$ & $\begin{array}{c}\text { Elong, } \\
\%\end{array}$ & $\begin{array}{l}\text { UTS, } \\
\text { MPa }\end{array}$ & $\begin{array}{c}\text { Elong, } \\
\%\end{array}$ \\
\hline$[001]$ & 1251 & 25.3 & 1128 & 30.5 & 1033 & 33.8 & 906 & 34.9 & 789 & 31.1 \\
\hline $\mathrm{XS}$ & 1154 & 22.6 & 1121 & 26.0 & 1010 & 20.6 & 904 & 17.5 & 846 & 19.0 \\
\hline $\mathrm{S}$ & 1176 & 15.7 & 1066 & 18.8 & 919 & 14.0 & 851 & 14.8 & 803 & 13.2 \\
\hline $\mathrm{M}$ & 1223 & 15.5 & 1013 & 17.4 & 937 & 8.2 & 849 & 6.0 & 766 & 3.4 \\
\hline $\mathrm{L}$ & 1194 & 16.8 & 1031 & 13.6 & 829 & 1.4 & 689 & 1.5 & 551 & 1.6 \\
\hline
\end{tabular}

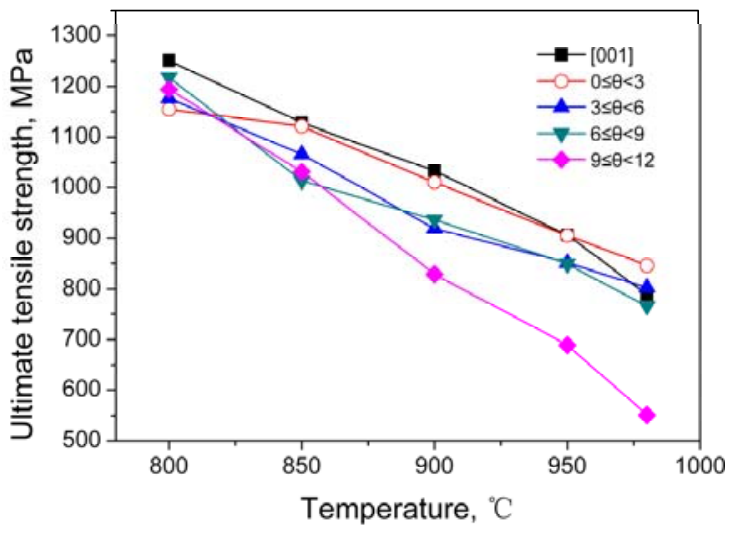

Figure 4. Effects of LAB on the ultimate tensile strength of DD6.

That is to say, when the temperature is below $980^{\circ} \mathrm{C}$, there is a distinct but rather minor influence of the $\mathrm{LAB}$ on the ultimate tensile strength under the condition of $\theta$ that is lower than $9^{\circ}$. When the temperature is below $850^{\circ} \mathrm{C}$, there is no significant effect of the LAB on the ultimate tensile strength and the ultimate tensile strengths of specimens are comparable to those of [001] specimens when the LAB is $0^{\circ}<\theta<3^{\circ}$.

The effects of LAB on the tensile elongation of DD6 alloy are shown in Figure 5. The elongation of the alloy with [001] orientation is superior to that of any specimen with LABs. It is interesting that the elongation of specimen with LABs increases from $800^{\circ} \mathrm{C}$ to $850^{\circ} \mathrm{C}$, except for the higher misorientation $\left(9^{\circ} \leq \theta<12^{\circ}\right)$. As the temperature increases from $850^{\circ} \mathrm{C}$ to $980^{\circ} \mathrm{C}$, the elongation of the alloy at a given misorientation decreases, except for the largest range of misorientation angles evaluated $\left(9^{\circ} \leq \theta<12^{\circ}\right)$. With increasing misorientation, the elongation of DD6 is decreased at a given temperature; this is especially true when the misorientation is more than $9^{\circ}$ at higher temperature than $850^{\circ} \mathrm{C}$. Overall, the effects of $\mathrm{LAB}$ on the ultimate tensile strength of DD6 are weaker than the effects on the tensile elongation. This is illustrated in Figure 6 which shows the relationship of tensile elongation, misorientation angle and temperature.

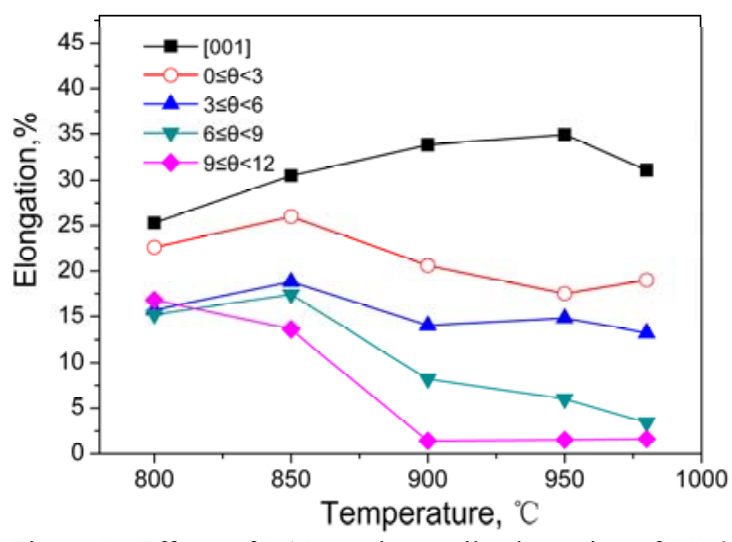

Figure 5. Effects of LAB on the tensile elongation of DD6.

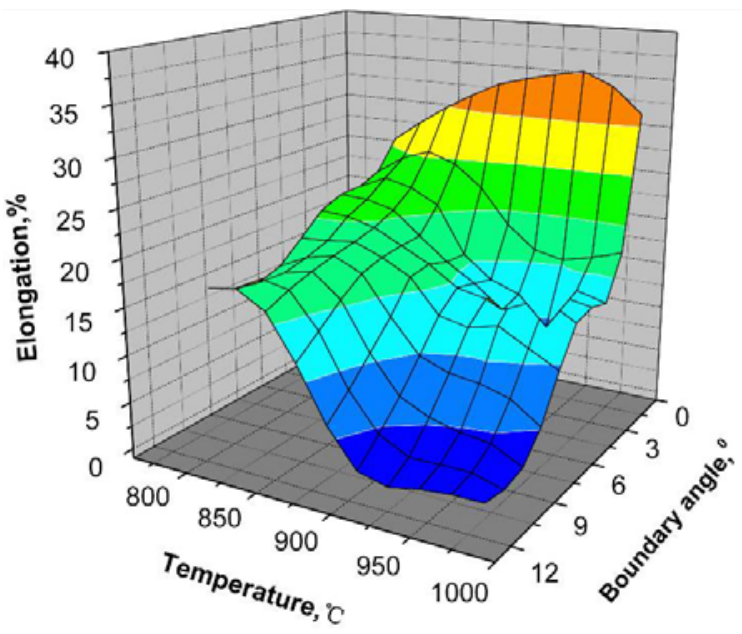

Figure 6. Relations among the tensile elongation, misorientation angle and temperature. 
Tensile Fracture. Tensile fracture surfaces and longitudinal photographs of the specimens with XS LAB are shown in Figure 7. At $800^{\circ} \mathrm{C}$, the fracture surface is almost a single plane paralleling the $\{111\}$ plane. The fracture surface is composed of many small planes at $900^{\circ} \mathrm{C}$. At $950^{\circ} \mathrm{C}$, fracture surface features characteristic of dendrites appears in specimens with XS LAB. Xray diffraction of the tensile fracture surface verifies that the small

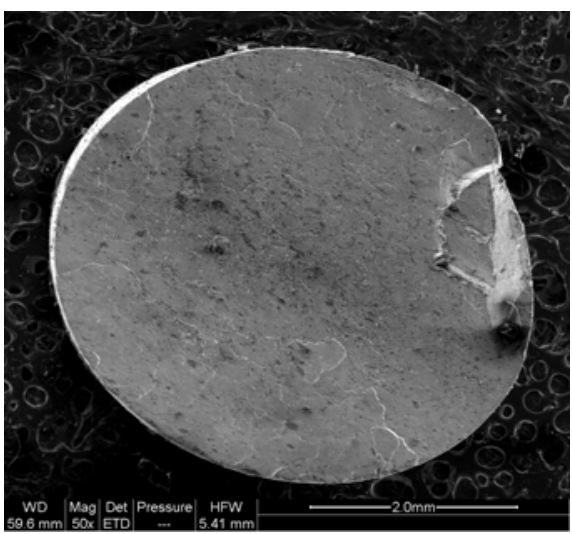

(a)

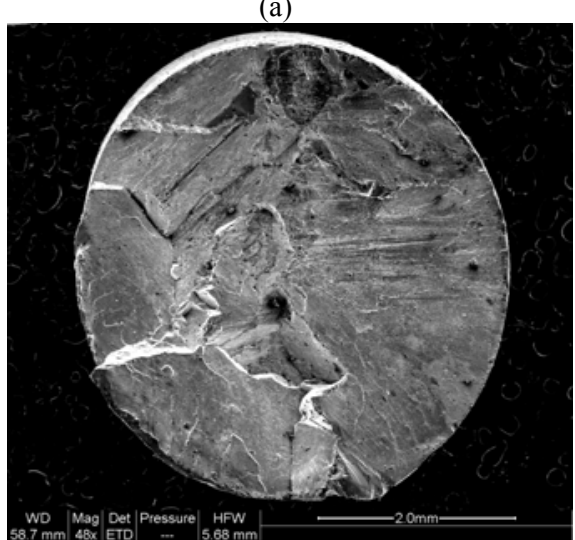

(c)

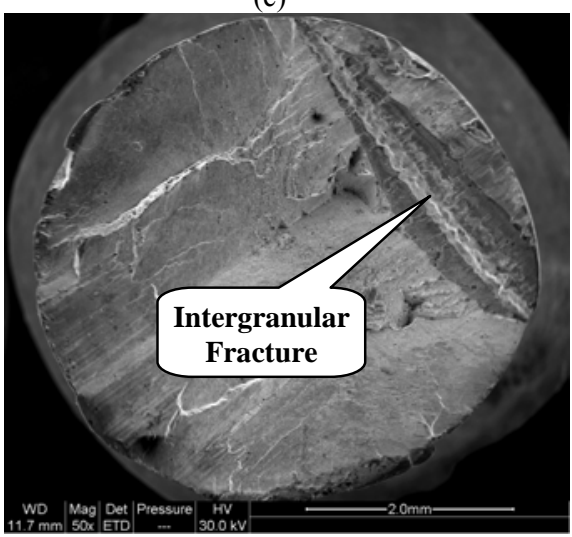

(e) planes are $\{111\}$. The fracture surface is characterized by quasicleavage features, as shown in Figure 7. Ebrahimi et al. observed that cleavage happens in the tensile fracture of single crystal superalloys and the cleavage plane is $\{111\}[11,12]$. In the other word, quasi-cleavage is the general fracture mechanism in single crystal superalloys, and it is independent of whether there is low angle boundary present or not.

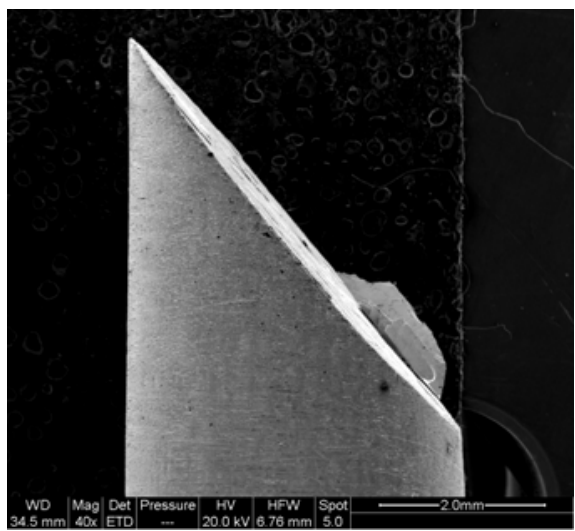

(b)

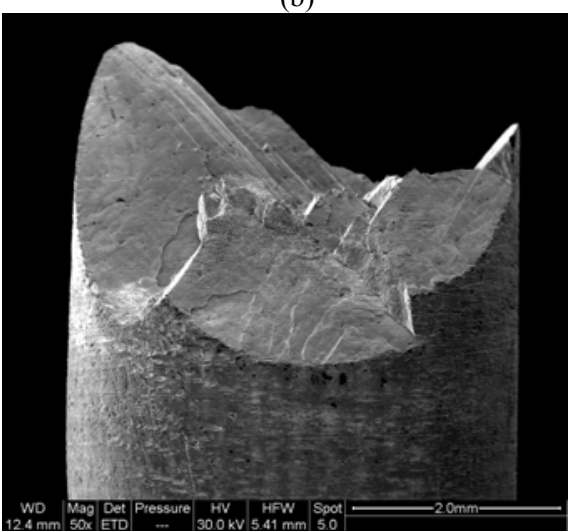

(d)

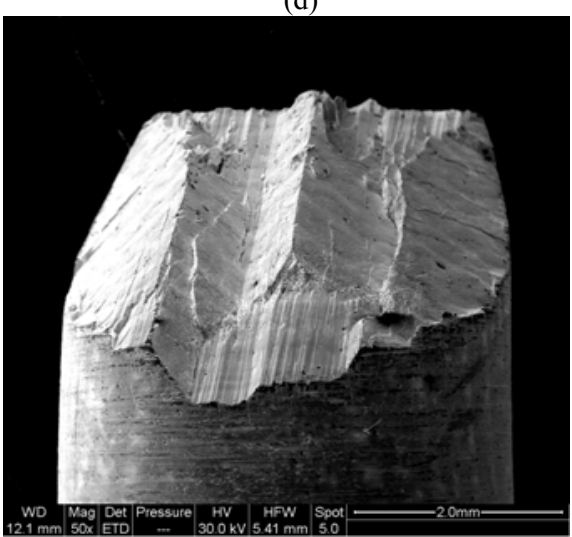

(f)

Figure 7. Tensile fracture surfaces and longitudinal photographs of the specimens with XS

(a) and (b) $800{ }^{\circ} \mathrm{C}$; (c) and (d) $900^{\circ} \mathrm{C}$; (e) and (f) $950^{\circ} \mathrm{C}$; (a), (c) and (e) fracture surface; (b), (d) and (f) longitudinal photograph.

Figure 8 shows intergranular fractograph with shrinkage pores in the XS specimen at $950^{\circ} \mathrm{C}$. Fracture surfaces with intergranular fracture features were observed at $950^{\circ} \mathrm{C}$ and $980^{\circ} \mathrm{C}$ in $\mathrm{XS}$ specimens, indicating that higher temperatures specimens with LABs exhibit this type of failure. Figure 9 shows that the slip bands on the surface of the tensile fracture specimen with XS at 
$850^{\circ} \mathrm{C}$, the fracture plane is parallel to $\{111\}$ slip plane. This demonstrates the small plane of the tensile fracture surfaces of the specimens is $\{111\}$ plane. Figure 10 shows the side of the tensile fracture specimen at $980^{\circ} \mathrm{C}$ with fracture surfaces mated after

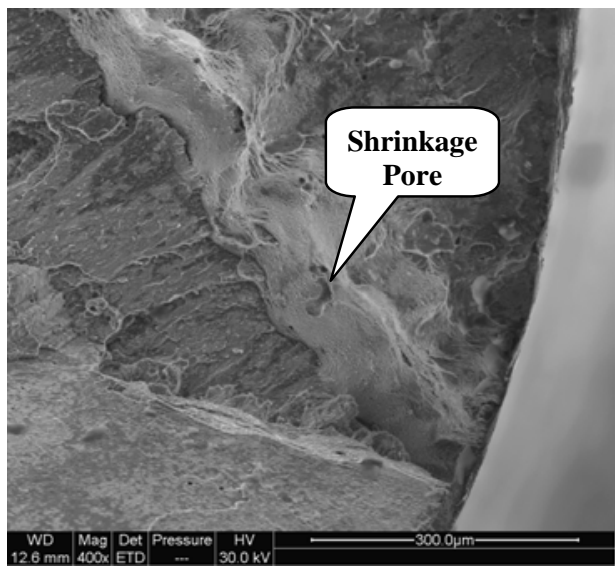

Figure 8 . Intergranular fractograph of the specimen with $\mathrm{XS}$ at $950^{\circ} \mathrm{C}$.

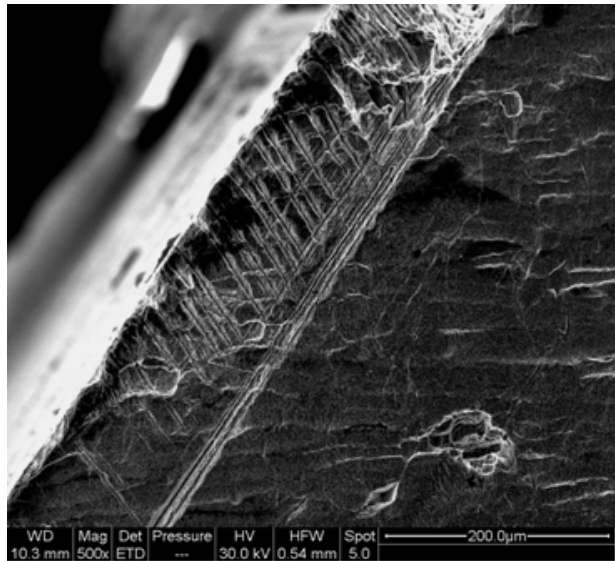

Figure 9. Slip bands on the surface of the tensile fracture specimen with $\mathrm{XS}$ at $850^{\circ} \mathrm{C}$.

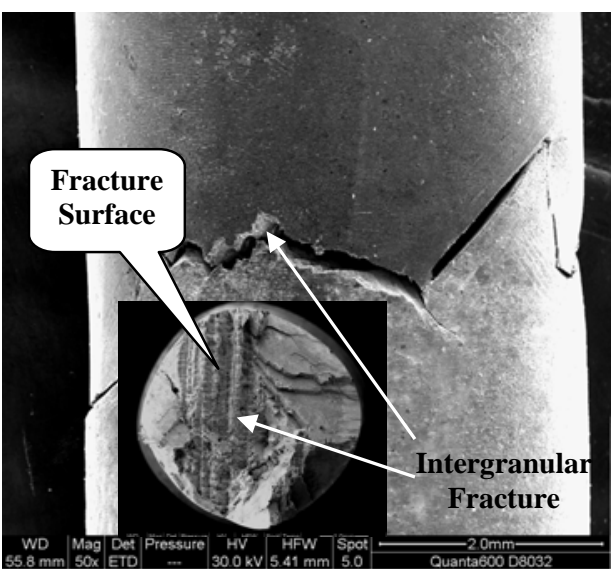

Figure 10. Surface of the tensile fracture specimen at $980^{\circ} \mathrm{C}$ with fracture surfaces mated. failure. The crack sequence is ascertained according to features observed on the two fractures faces. Under tensile loads, the fracture surface display mixed quasi-clevage and intergranular fracture.

\section{Creep Properties}

Creep Rupture Life. The creep rupture properties of the specimens of DD6 alloy with LAB and [001] orientation were performed at the conditions of $800^{\circ} \mathrm{C} / 700 \mathrm{MPa}, 850^{\circ} \mathrm{C} / 550 \mathrm{MPa}, 900^{\circ} \mathrm{C} / 450 \mathrm{MPa}$ and $980^{\circ} \mathrm{C} / 250 \mathrm{MPa}$. The data is listed in Table IV. The creep rupture lives of DD6 alloy with [001] orientation provide an obvious advantage relative to those of the alloy with $\mathrm{LAB}$ at the same test condition [9]. With increasing temperature and decreasing stress, the effects of LAB on the creep rupture lives decrease. Temperature has a major effect on the creep rupture lives of the specimens with $\mathrm{LAB}$.

In this study the creep rupture lives decrease with increasing misorientation at the same test conditions; particularly the creep rupture lives are very low when the misorientation is more than $9^{\circ}$. When the misorientation is less than $6^{\circ}$, the creep rupture lives of the alloy with LAB are lower than those with [001] orientation under the condition of $800^{\circ} \mathrm{C} / 700 \mathrm{MPa}$; while the creep rupture lives of the alloy with LAB are basically comparable to those with [001] orientation under the conditions of $850^{\circ} \mathrm{C} / 550 \mathrm{MPa}$ $900^{\circ} \mathrm{C} / 450 \mathrm{MPa}$ and $980^{\circ} \mathrm{C} / 250 \mathrm{MP}$. E.W. Ross et al. indicated that the transverse rupture strength would not be reduced if the misorientation between the adjacent grains was $6^{\circ}$ or less [4]. In this study, the transverse creep rupture lives of DD6 alloy with LAB are less than, whereas comparable to those with [001] orientation under the conditions of $850^{\circ} \mathrm{C} / 550 \mathrm{MPa}$, $900^{\circ} \mathrm{C} / 450 \mathrm{MPa}$ and $980^{\circ} \mathrm{C} / 250 \mathrm{MPa}$ when the misorientation is less than $6^{\circ}$, basically being in agreement with the results of E.W. Ross et al. [4], and the law of this study is partially consistent with the results performed by D.M. Shah et al. [7].

Creep Fracture. The microstructures of the creep ruptured specimens indicate that the coarsening of the $\gamma^{\prime}$ phase of the alloy with $\mathrm{LAB}$ is not significant in the specimens crept at $800^{\circ} \mathrm{C}$, while the rafting of the $\gamma^{\prime}$ phase is obvious in the $850^{\circ} \mathrm{C}, 900^{\circ} \mathrm{C}$ and $980^{\circ} \mathrm{C}$ crept samples. At temperatures higher than $850^{\circ} \mathrm{C}$, diffusion has a strong influence on creep deformation and as a result the creep ruptured specimens have many micro-cavities and rafting is readily apparent.

The creep rupture surfaces of the specimens with LAB at $800^{\circ} \mathrm{C} / 700 \mathrm{MPa}$ are shown in Figure 11. Features characteristic of both quasi-cleavage and intergranular fracture are apparent on creep rupture surfaces of LAB specimens. The rupture surfaces are mainly characterized by intergranular fracture in the $\mathrm{M}$ and $\mathrm{L}$ specimens, indicating the obvious effects of $\mathrm{LAB}$ on the transverse creep properties. The creep rupture lives decrease with increasing misorientation at a given set of test conditions. The creep rupture surfaces of the specimens with $\mathrm{XS}$ are shown in Figure 12 , at $800^{\circ} \mathrm{C} / 700 \mathrm{MPa}, 850^{\circ} \mathrm{C} / 550 \mathrm{MPa}, 900^{\circ} \mathrm{C} / 450 \mathrm{MPa}$ and $980^{\circ} \mathrm{C} / 250 \mathrm{MPa}$, respectively. In the XS specimens with increasing temperature and decreasing stress the amount of fracture features characteristic of intergranular fracture on the surface decreases, while features characteristic of dimples become apparent. The rectangular dimple features apparent on the crept fracture surfaces of the [001] and $\mathrm{S}$ specimens are shown in Figure 13 at $900^{\circ} \mathrm{C} / 450 \mathrm{MPa}$. 
Table IV Creep rupture properties of the specimens of DD6 alloy with LAB and [001] orientation

\begin{tabular}{|c|c|c|c|c|c|c|c|c|}
\hline \multirow{2}{*}{ Specimen } & \multicolumn{2}{|c|}{$800^{\circ} \mathrm{C} / 700 \mathrm{MPa}$} & \multicolumn{2}{|c|}{$850^{\circ} \mathrm{C} / 550 \mathrm{MPa}$} & \multicolumn{2}{c|}{$900^{\circ} \mathrm{C} / 450 \mathrm{MPa}$} & \multicolumn{2}{c|}{$980^{\circ} \mathrm{C} / 250 \mathrm{MPa}$} \\
\cline { 2 - 9 } & Life, hrs & RA., $\%$ & Life, hrs & RA., $\%$ & Life, hrs & RA., $\%$ & Life, hrs & RA., $\%$ \\
\hline$[001]$ & 429 & 40.0 & $489+22^{*}$ & 25.9 & 304 & 36.9 & 268 & 45.3 \\
\hline XS & 189 & 10.0 & $508+3^{*}$ & 33.0 & 266 & 36.0 & 195 & 21.2 \\
\hline S & 220 & 8.8 & 384 & 12.0 & 231 & 21.3 & 195 & 43.6 \\
\hline M & 83 & 7.9 & 64 & 4.5 & 52 & 6.7 & 42 & 8.4 \\
\hline L & 3 & 4.0 & 3 & 10.4 & 2 & 10.4 & 0.1 & 7.1 \\
\hline
\end{tabular}

Note: * indicate the creep time loaded to fracture under the stress of $650 \mathrm{MPa}$ after $550 \mathrm{MPa}$.

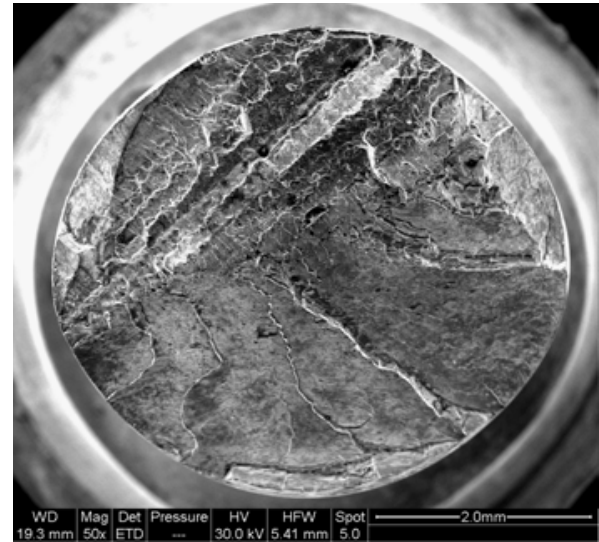

(a)

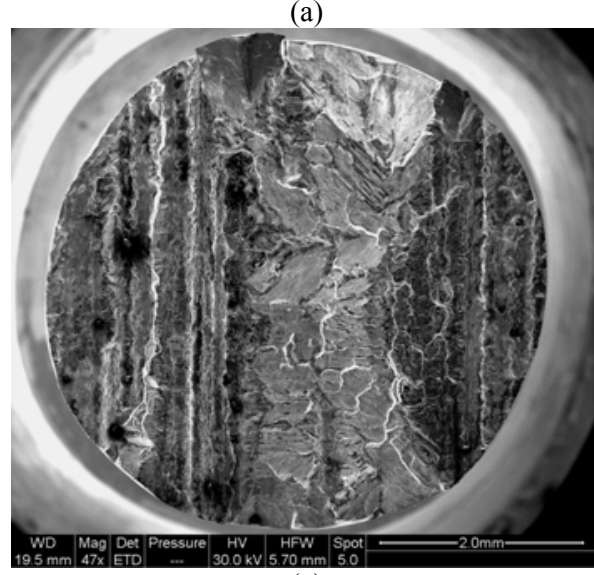

(c)

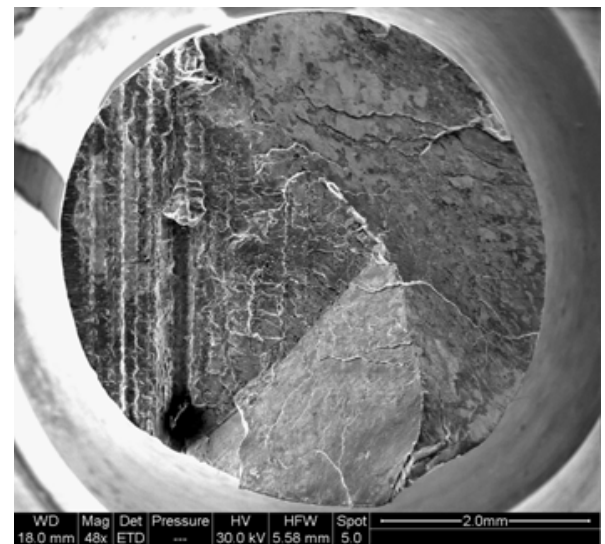

(b)

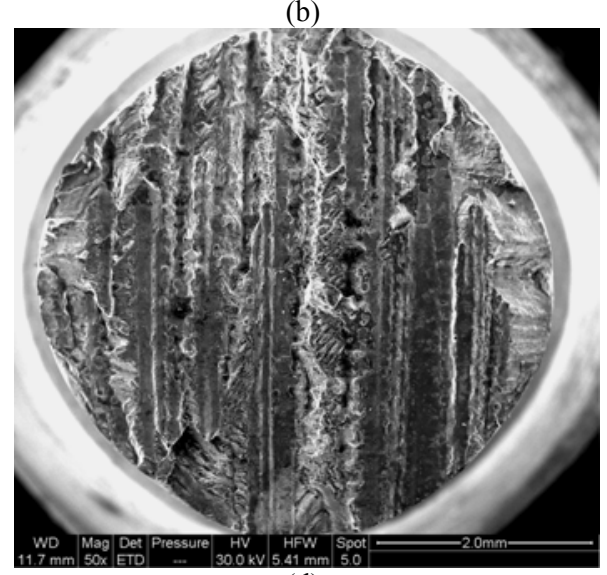

(d)

Figure 11. Creep rupture surfaces of the specimens with $\mathrm{LAB}$ at $800^{\circ} \mathrm{C} / 700 \mathrm{MPa}$ (a) XS; (b) S; (c) M; (d) L.

These rectangular dimples were only observed on the creep fracture surfaces of the specimens with LABs, and not on the tensile fracture surfaces. It is notable that the rectangular dimples can be observed in both the [001] and LAB specimens. It is found that the fracture of the rectangular dimples happens along $\{111\}$ planes. It is hypothesized that microcavities, around which the alloy appears to exhibit quasi-cleavage fracture, in general, are rectangular and make the fracture surfaces have the characteristic of the dimple.

It is found that there is no obvious microstructure difference between the vicinity of LAB and dendrite itself of DD6 alloy after fully heat treated. The effects of $\mathrm{LAB}$ on the mechanical properties at elevated temperatures result from the fact that the inherent strength of grain boundary is lower than that of the dendrite and the strength of dendrite cores is higher than that of interdendritic regions. The tensile and creep properties of the alloy with LABs are lower than those with [001] orientation, which originates from the facts that there are low angle boundaries and interdendritic regions which are perpendicular to the axis of stress.

For the tensile and creep properties, generally, a LAB has little effect on the DD6 alloy when the misorientation of the LAB is low. It must be stressed that the quasi-cleavage is a fracture mechanism, it does not represent the plasticity of single crystal materials. For example, the fracture surfaces of DD6 alloy with 
XS LABs exhibit quasi-cleavage features following tensile testing as shown in Figure 7, but the alloy has good tensile elongations as listed in Table III. The crack propagation along low angle boundary in the creep rupture specimen with M LAB is shown in Figure 14 at $850^{\circ} \mathrm{C} / 550 \mathrm{MPa}$, this shows the intergranular fracture.

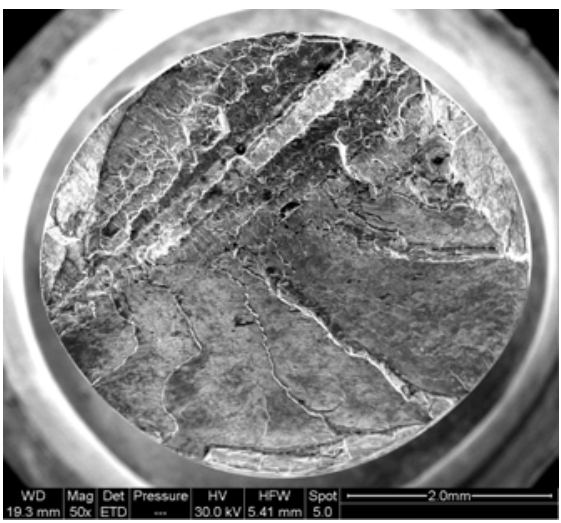

(a)

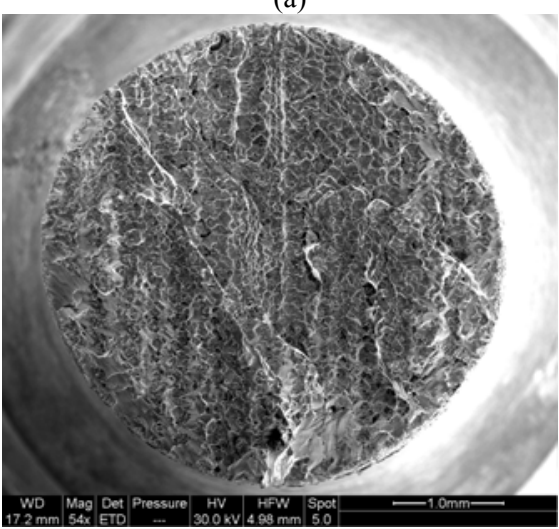

(c)
The surfaces of the creep fracture of the specimens with S LABs are shown in Figure 15 at $800^{\circ} \mathrm{C} / 700 \mathrm{MPa}$. By observing the mated crept fracture surfaces, the alloy appears to fracture first intergranularly, followed by quasi-cleavage.

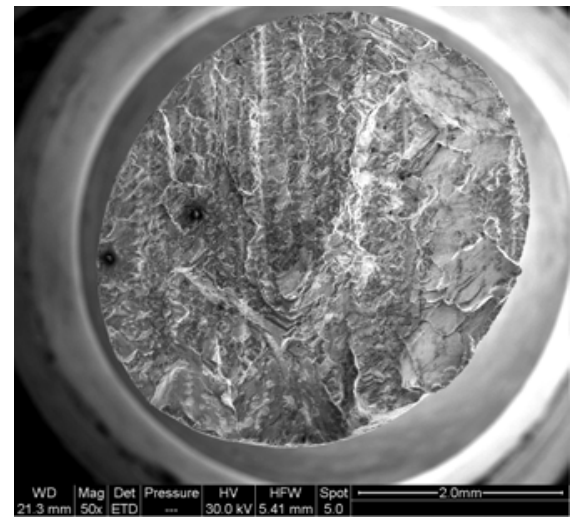

(b)

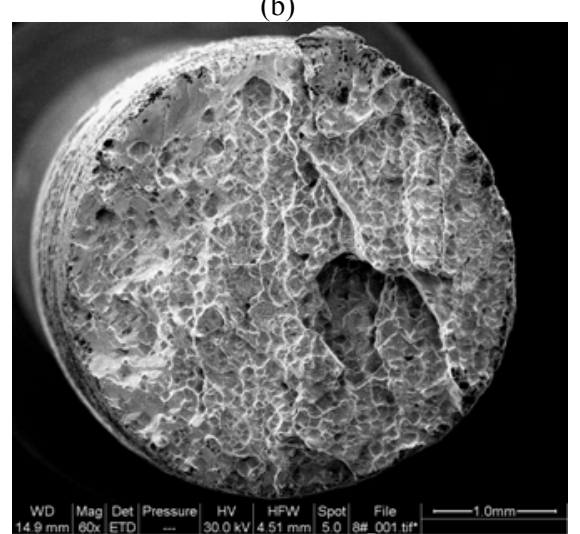

(d)

Figure 12. Creep rupture surfaces of the specimens with $\mathrm{XS}$ at the different test conditions (a) $800^{\circ} \mathrm{C} / 700 \mathrm{MPa}$; (b) $850^{\circ} \mathrm{C} / 550 \mathrm{MPa}$; (c) $900^{\circ} \mathrm{C} / 450 \mathrm{MPa}$; (d) $980^{\circ} \mathrm{C} / 250 \mathrm{MPa}$.

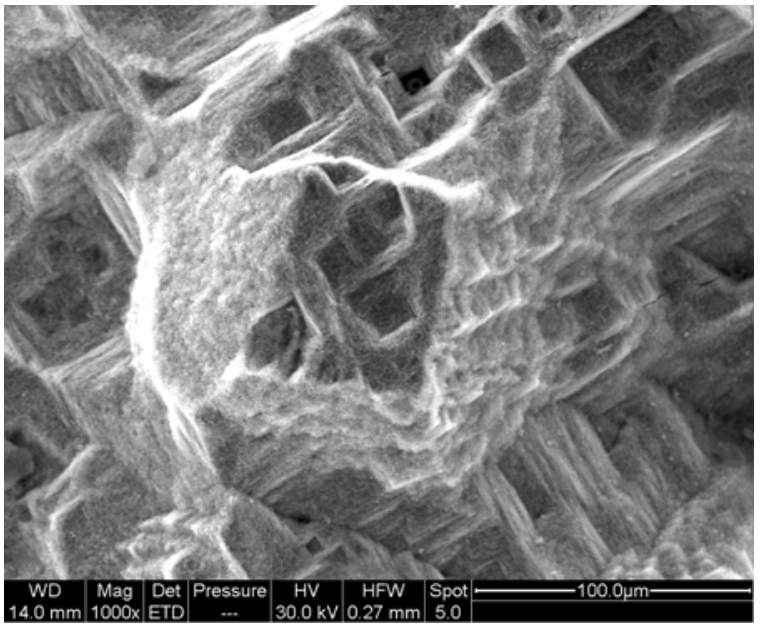

(a)

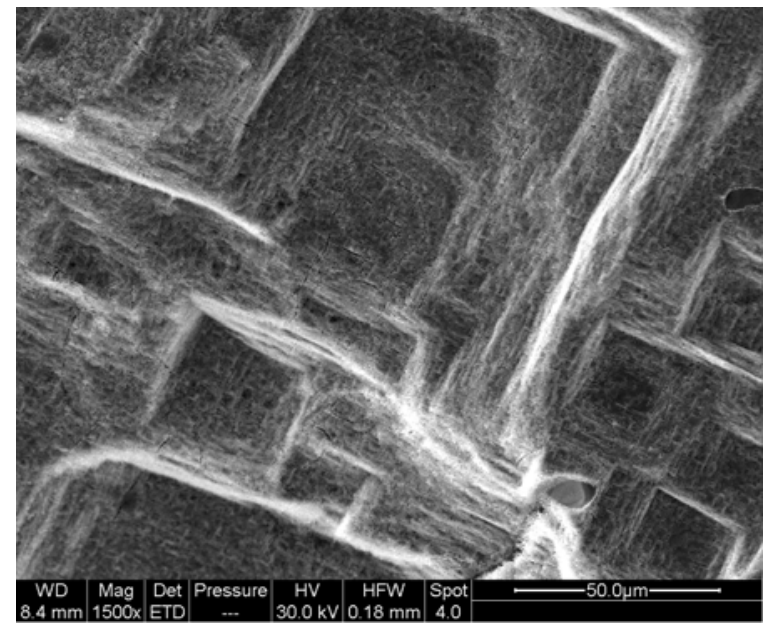

(b)

Figure 13. Rectangular dimples on the creep fracture surfaces of the specimens at $900^{\circ} \mathrm{C} / 450 \mathrm{MP}$ (a) [001]; (b) $\mathrm{S}$ 


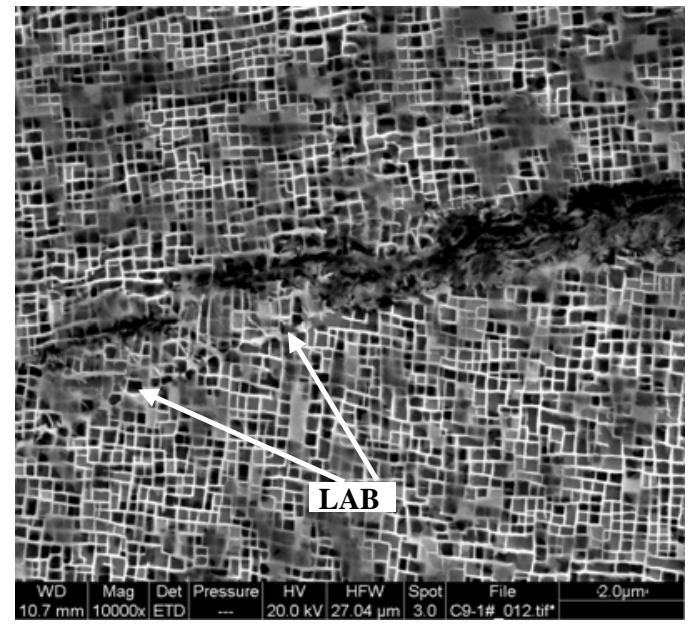

Figure 14. Crack propagation along the $\mathrm{LAB}$ in the creep rupture specimen with $\mathrm{M}$ at $850^{\circ} \mathrm{C} / 550 \mathrm{MPa}$.

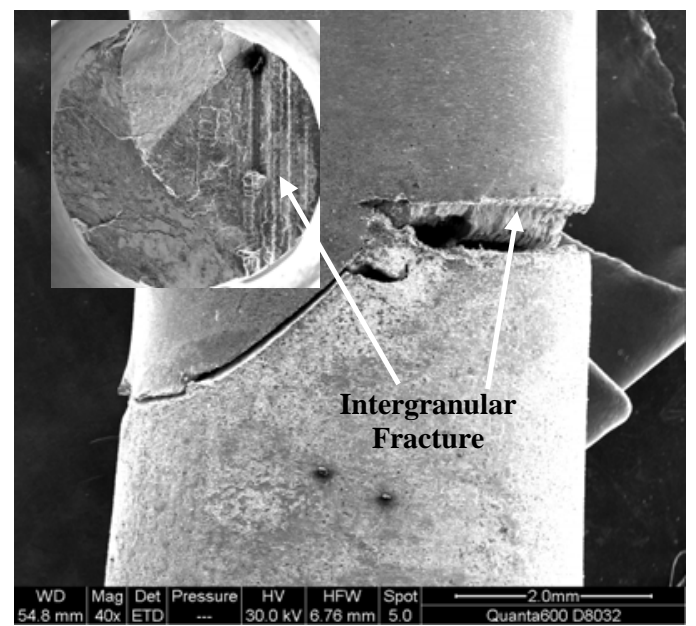

Figure 15. Surfaces of the creep fracture of the $\mathrm{S}$ specimen at $800^{\circ} \mathrm{C} / 700 \mathrm{MPa}$ with fracture surfaces mated.

\section{Summary}

A study was performed to assess the effects of low angle boundary on the mechanical properties of a second generation single crystal alloy DD6. The test results show that the LAB has a little effect on the tensile and creep properties of DD6 alloy when the misorientation of LAB is low $\left(\theta<6^{\circ}\right)$. The misorientation angle of the LAB of DD6 alloy does not have a major impact on the ultimate tensile strength at a given test temperature, except for higher misorientation angle $\left(9^{\circ} \leq \theta<12^{\circ}\right) \mathrm{LAB}$. With the increase of the temperature from $850^{\circ} \mathrm{C}$ to $980^{\circ} \mathrm{C}$, reduced elongation is evident for specimens with $\mathrm{LAB}$ at the same misorientation. With increasing $\mathrm{LAB}$ misorientation, the elongation is decreased at the same temperature; the elongation is remarkably decreased when the misorientation is more than $9^{\circ}$ and temperatures greater than $850^{\circ} \mathrm{C}$. It is notable that effects of $\mathrm{LAB}$ on the ultimate tensile strength are weaker than those on the tensile elongation.
There is a general trend for the creep rupture lives to decrease as the misorientation increases at the same test conditions. Under the conditions of $900^{\circ} \mathrm{C} / 450 \mathrm{MPa}$ and $980^{\circ} \mathrm{C} / 250 \mathrm{MPa}$ when the misorientation is less than $6^{\circ}$, then there is an exception to this trend and the lives are roughly comparable.

Temperature has an obvious effect on the creep rupture lives of the alloy with LAB. When temperature is higher than $850^{\circ} \mathrm{C}$, the diffusion has a strong influence on the creep deformation, so that the many micro-cavities and obvious rafting can be observed in the creep rupture specimens. The characteristic of quasi-cleavage and intergranular fracture were observed on the tensile and creep rupture surfaces with $\mathrm{LAB}$. With the test temperature increasing and stress decreasing, the characteristic of the intergranular fracture is becoming weaker, and the characteristic of the dimple fracture is apparent at $980^{\circ} \mathrm{C} / 250 \mathrm{MPa}$, when the misorientation of $\mathrm{LAB}$ is low.

It is found that the fracture of the rectangular dimples happens along $\{111\}$ planes. It is hypothesized that microcavities, around which the alloy appears to exhibit quasi-cleavage fracture, in general, are rectangular and make the fracture surfaces have the characteristic of the dimple. The quasi-cleavage rupture is independent of whether there is LAB or not. It must be stressed that the quasi-cleavage is a fracture mechanism, it does not represent the plasticity of single crystal materials.

\section{References}

1. M. Gell, D.N. Duhl and A.F. Giamei, "The Development of Single Crystal Superalloy Turbine Blades," Superalloys 1980, ed. J.K. Tien et al. (Metals Park, OH: American Society for Metals, 1980), 205-214.

2. A.D. Cetel and D.N. Duhl, "Second Generation Nickel-Base Single Crystal Superalloy," Superalloys 1988, ed. S. Reichman et al. (Warrendale, PA: The Metallurgical Society, 1988), 235-244.

3. K. Harris et al., "Development of the Rhenium Containing Superalloys CMSX-4 and CM186LC for Single Crystal Blade and Directionally Solidified Vane Applications in Advanced Turbine Engines," Superalloys 1992, ed. S.D. Antolovich et al. (Warrendale, PA: TMS, 1992), 297-306.

4. E.W. Ross and K.S. O’Hara, "René N4: A First Generation Single Crystal Turbine Airfoil Alloy with Improved Oxidation Resistance, Low Angle Boundary Strength and Superior Long Time Rupture Strength," Superalloys 1996, ed. R.D. Kissinger et al. (Warrendale, PA: TMS, 1996), 1925 .

5. W.S. Walston et al., "Rene'N6: Third Generation Single Crystal Superalloy," Superalloys 1996, ed. R.D. Kissinger et al. (Warrendale, PA: TMS, 1996), 27-34.

6. B.B. Seth, "Superalloys-The Utility Gas Turbine Perspective," Superalloys 2000, ed. T.M. Pollock et al. (Warrendale, PA: TMS, 2000), 3-16.

7. D.M. Shah and A. Cetel, "Evaluation of PWA1483 for Large 
Single Crystal IGT Blade Applications," Superalloys 2000, ed. T.M. Pollock et al. (Warrendale, PA: TMS, 2000), 295304.

8. K. Harris and J.B. Wahl, "Improved Single Crystal Superalloys, CMSX-4 (SLS)[La+Y] and CMSX-486," Superalloys 2004, ed. K.A. Green et al. (Warrendale, PA: TMS, 2004), 45-52.

9. J.R. Li et al., "A Low-Cost Second Generation Single Crystal Superalloy DD6," Superalloys 2000, ed. T.M. Pollock et al. (Warrendale, PA: TMS, 2000), 777-783.

10. Li Jiarong, Jin Haipeng and Liu Shizhong, "Stress Rupture Properties and Microstructures of the Second Generation Single Crystal Superalloy DD6 after Long Term Aging at $980^{\circ} \mathrm{C}, "$ Rare Metal Materials and Engineering, 36(10) (2007), 1784-1787.

11. F. Ebrahimi, J. Yanevich and D.P. Deluca, "Deformation and Fracture of the PWA 1472 Superalloy Single Crystal," Acta Materialia, 48 (2000), 469-479.

12. Zhao Jinqian et al., "Effect of Low Angle Grain Boundary on Tensile Properties of Single Crystal Superalloy DD6 at $980^{\circ} \mathrm{C}, "$ Rare Metal Materials and Engineering, 36(12) (2007), 2232-2235. 